\title{
Parallel Working Memory for Spatial Location and Food-Related Object Cues in Foraging Pigeons: Binocular and Lateralized Monocular Performance
}

\author{
Helmut Prior ${ }^{1}$ and Onur Güntürkün \\ AE Biopsychologie, Ruhr-Universität Bochum, D-44780 Bochum, Germany
}

\begin{abstract}
During foraging, animals can increase their success by both remembering feeding sites and remembering food-related object cues. Because earlier studies have tested either the site or object memory in isolation, the aim of the present study was to evaluate how efficiently birds can utilize both memories simultaneously. Furthermore, the idea was tested that lateralization might be the principle of brain organization that allows for efficient parallel processing. Pigeons learned to search for food in a complex maze with 16 baited sites. To obtain the maximum reward they had to perform two tasks in parallel, a spatial working memory task and an object-specific working memory task. Birds performed well on this dual task but, compared with spatial working memory alone, they were impaired during the first choices of a trial (Experiment 1). When the left and the right brain hemispheres were tested separately by means of monocular occlusion (Experiment 2), object discrimination was better when birds used their right eye/left hemisphere. This was most pronounced during the first choices of a trial. On the spatial component of the task, performance on binocular trials was better than on monocular trials, but monocularly both hemispheres performed at the same level. Results show that on this dual task, discrimination of food-related object cues predominantly involved the left brain hemisphere whereas both hemispheres contributed equally to spatial performance.
\end{abstract}

Animals searching for food can improve their foraging success considerably by learning (e.g., Pulliam 1981; Lewis 1986; Garber 1989; Benhamou 1994; Sherry 1998). This advantage results in several costs. Aside from the investment into the development and maintenance of the neural structures carrying out the learning and memory processes, there are also cognitive costs caused by the fact that certain operations can have an impairing effect on other operations (Dukas 1998). For example, when blue jays (Cyanocitta cristata) learned to respond to pictures of moths that were difficult to see against the background, they performed at a much higher level during sessions with only one moth species than during sessions with two moth species presented alternately (Pietrewicz and Kamil 1979). Sticklebacks (Spinachia spinachia) more efficiently learned to attack and handle prey if they fed on one rather than on two types of prey (Croy and Hughes 1991). In addition to demonstrating the importance of cognitive costs, these studies suggest that an adaptive behavioral strategy to circumvent decrements in performance might be to temporarily focus on only one of several types of food available. This was also shown in wood pigeons (Columba palumbus), which feed on a diet similar to that of the species tested in this study-

${ }^{1}$ Corresponding author.

E-MAIL helmut.prior@ruhr-uni-bochum.de; FAX 49234 3214377.

Article and publication are at www.learnmem.org/cgi/doi/ $10.1101 / \mathrm{lm} .36201$. the pigeon, Columba livia. When wood pigeons were experimentally presented with different combinations of seeds, foraging success (as indicated by crop content) was highest in those individuals that had selected a single type of seed (Murton 1971). This suggests that selectivity per se can increase foraging success. Aside from this, learned temporary selective feeding may be important if several types of food are available but one type yields more gain than others when constraints such as encounter rate and handling time are considered (e.g., Krebs et al. 1977).

A second factor of paramount importance for efficient foraging is patch selection. When birds search for food, it is advantageous to abandon diminished patches for more profitable ones. By memorizing the state of different patches, birds can improve foraging success (Kamil 1978), particularly if other demands - such as defending the territory constrain the time available for foraging (Healy and Hurly 1998).

In the laboratory, working memory for feeding sites was extensively studied in paradigms involving sampling without replacement procedures, such as the radial maze (Olton and Samuelson 1976) and its analogs (Balda and Kamil 1988). Pigeons (C. livia) have demonstrated fairly good capabilities on such tasks. Although an early study (Bond et al. 1981) suggested poor radial-maze learning, later investigations demonstrated good learning on the radial maze or its analogs if the pigeons had sufficient training. Roberts and Van Veldhuizen (1985) showed that pigeons achieve a per-

LEARNING \& MEMORY 8:44-51 @ 2001 by Cold Spring Harbor Laboratory Press ISSN1072-0502/01 \$5.00

$$
\begin{array}{lllllllllllllll}
\text { L } & E & A & R & N & I & N & G & \mathbf{Z} & M & E & M & O & R & Y \\
\text { www.learnmem.org } & & & &
\end{array}
$$


formance level similar to rats on a radial maze. Spetch and Edwards (1986) found better performance on a radial-maze analog in a ground-feeding task than on a similar task requiring the birds to fly. The pigeon's memory is based on local and global cues (Spetch and Edwards 1988), and performance is higher if global landmark cues are reliable between trials (Spetch and Honig 1988). The pigeons' spatial working memory appears to last for at least 30-60 min (Spetch 1990).

This study was designed to simultaneously test working memory for places and working memory for food-related color cues. The first question was whether overall performance would be impaired if the birds had to learn and remember a color cue signaling a reward while running a spatial working memory task. Pigeons had to learn a complex maze with 16 baited sites (Fig. 1). In the first stage of the experiment, the color indicating the reward was held constant. During subsequent serial reversal training, pigeons were accustomed to changes in the color indicating the reward. Finally, the reward color was changed randomly from trial to trial.

Thus, the subjects could not know before a trial which color was rewarded. They had to learn this in the first choice(s) of a trial and keep it in their working memory until the trial ended. The concept of working memory used here refers to the common operational definition of working memory (memory for trial-unique stimulus components) and reference memory (memory for features remaining invariant for a number of trials). Comparison of performance with constant color cues and trial-specific color cues gives an estimate of the extent to which foraging success is challenged by additional demands on working memory.

A second main question of our study addresses the problem of how the brain deals with the processing of such a parallel task. One possibility for avoiding a substantial impairment would be that different brain systems are in

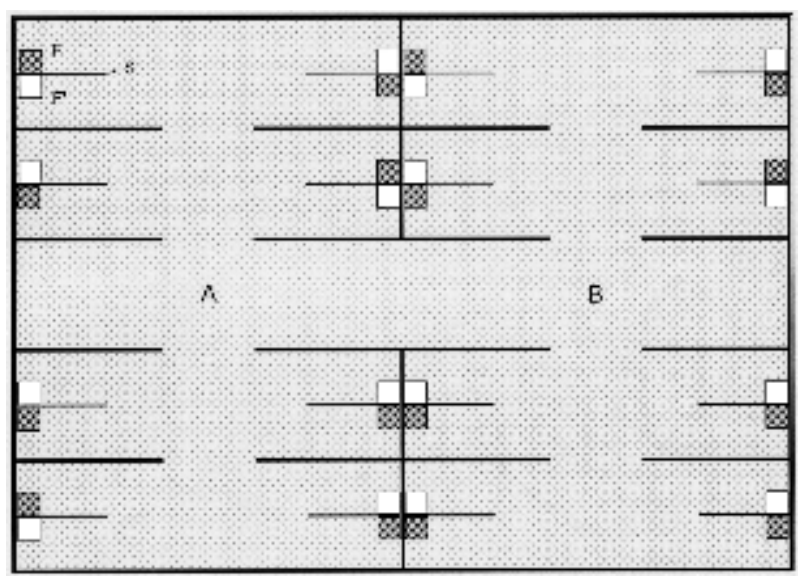

Figure 1 View of the maze. The subjects started a trial from the locations indicated by $A$ and $B$. (S) separation; $\left(F^{\prime}\right)$ food bowls of different color. charge of the task. Contrary to tests with very similar cues, such as those used during the discrimination of different moths by jays, it is conceivable that discrimination of foodrelated color cues and patch selection are different enough to involve differing multiple memory systems (Sherry and Schacter 1987). A common way of segregating different cognitive processes into different neural circuits is lateralization (Vallortigara et al. 1999). In birds, tests for lateralization often use the technique of reversible monocular occlusion. Because of the virtually complete decussation of the avian optic nerve and the lack of a corpus callosum, visual input can be restricted to one hemisphere by covering the ipsilateral eye. Performance with the right eye (left eye covered) then predominantly reflects processing in the left brain hemisphere and vice versa. From studies using this method, there is consistent evidence in several species for a right eye/left hemisphere advantage for the discrimination of local cues (for review, see Güntürkün 1997). Therefore, we expected lateralization of the color discrimination component of the dual task in favor of the right eye/left hemisphere.

Regarding the spatial task component, the situation is less clear. Using monocular occlusion, Rashid and Andrew (1989) found more systematic and spatially-focused search behavior in domestic chicks when they used the left eye. Also using monocular occlusion, Clayton and Krebs (1994a) tested the memory of food-storing and non-food-storing passerine birds for feeders that had a trial-unique location within the experimental room and also a trial-unique color pattern. When, after a short retention interval, birds were given dissociation tests during which the correct feeder changed its position and a different feeder was placed at the original location, subjects predominantly remembered the local cues of the feeder if they used their right eye and the spatial location within the room if they used their left eye. These results are consistent with the hypothesis of a complementary advantage of the avian right hemisphere on spatial tasks (cf. Bradshaw and Rogers 1993).

In contrast, the only study on lateralization of spatial performance in the pigeon that investigated lateralization during homing reported right eye/left hemispheric superiority (Ulrich et al. 1999). This indicates that pigeons might show a different pattern of lateralization than the few other avian species tested so far. It also might hint at differences between different spatial tasks. Regarding this study, an important feature of the task is related to memory strategies. Although not yet tested in birds, closely similar findings in humans and rats (Cook et al. 1985; Kesner and Spain 1988) suggest that a memory strategy involving a switch from retrospective to prospective coding halfway through the task might be a general principle of how brains with a limited working memory capacity solve such a task. The brain mechanisms controlling this process could have a different pattern of lateralization than those concerned with

\section{$\begin{array}{lllllllllllllll}\text { www.learnmem.org } & & & & & & & & & & & & \end{array}$}


storing single spatial locations or dealing with the physical properties of spatial cues. But given the present state of knowledge, any prediction regarding the possible lateralization of the spatial component of the pigeon's task should be made with caution.

The aim of the first experiment was to test whether pigeons using both eyes and both brain hemispheres would perform efficiently on a dual task (a spatial working memory task and an object-specific working memory task).

The goal of the second experiment was to test whether there was lateralization, or perhaps a double lateralization, in that the left hemisphere focuses on the color cue and the right hemisphere on the spatial working memory. By using monocular occlusion and comparing performance with both eyes (the left eye and the right eye) we investigated how efficiently each brain hemisphere alone performs the task and whether there are interhemispheric differences in the working memory for the object-specific or the spatial memory component of the dual task.

\section{RESULTS}

\section{Experiment 1}

During initial testing with spatial working memory only, pigeons made $11.7 \pm 0.33$ choices leading to a reward. This level of performance was caused by the spatial task component, whereas birds always chose the correct color throughout. Performance levels differed significantly from random expected probability for correct spatial choice alone ( $t=7.262$, df $=4, P<0.001)$. Performance during the 10 test trials was stable with small variance across trials $(F[9,36]=0.742, P>0.6)$.

During serial reversal training, pigeons learned the color reversal quickly. On the first reversal trial, all birds exclusively chose the incorrect color, which indicates that choice of the rewarded food bowl was based on color alone and not on possible other (e.g., odor) cues. Figure 2 shows that pigeons achieved a fairly high performance level within five reversals. Number of choices to criterion declined rapidly. ANOVA with reversal block as repeated measure revealed a significant difference across reversal blocks $(F[5,20]=7.231, P<0.002)$. The average number of correct choices on the first reversal trial increased from $0.0 \pm 0.00$ on the first reversal block to $12.8 \pm 0.58$ on the sixth reversal $(F[5,20]=20.029, P<0.001)$.

Figure 3 compares the pigeons' performance on trials with and without object-specific working memory. On the dual task, overall success was reduced to $10.8 \pm 0.50$, as compared to $11.7 \pm 0.33$ in the spatial-memory-only task.

ANOVA revealed a significant effect of memory condition $(F[1,4]=9.335, P<0.02)$, a trend for an effect of choice block $(F[2,8]=3.557, P<0.1)$ and a significant interaction $(F[2,8]=4.743, P<0.05)$. Planned comparisons of performance within each block of five choices showed

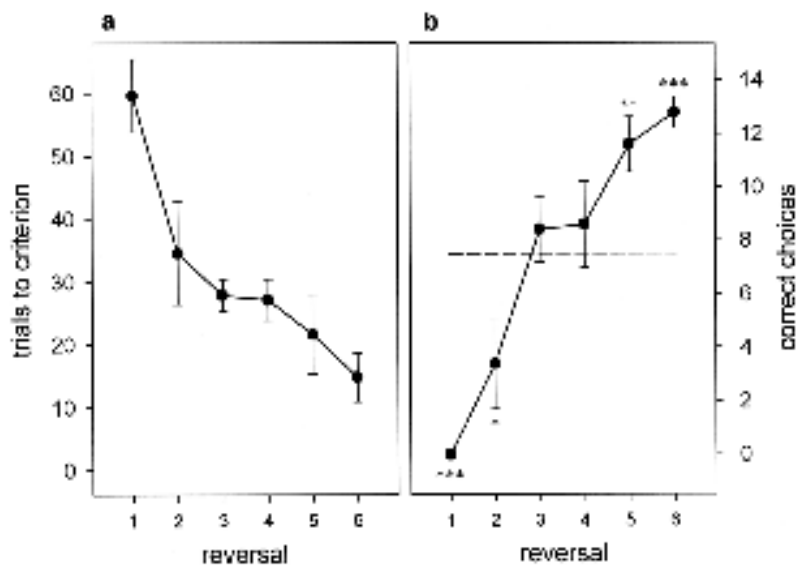

Figure 2 Serial reversal learning. Panel a shows the number of choices necessary for the birds to achieve criterion on successive reversal blocks. Panel $b$ gives the performance on the first trial of a given reversal block. The dotted line indicates random performance level. Asterisks indicate deviation from chance: Single asterisk: $P<.05$; double asterisk: $P<.01$; triple asterisk: $P<.001$.

that pigeons who had to learn the correct color within a single trial were impaired during the first five choices $(P<0.01)$ but not on the second $(P>0.3)$ or third $(P>0.9)$ block of five choices (see Fig. 3).

Separate comparison of correct spatial choices between the two memory conditions showed a slight (3.5\%) but not significant difference for the whole trial, and a significant reduction from $94 \%$ to $80 \%$ correct choices during the first block of five choices $(t=4.518, \mathrm{df}=4, P<0.02)$. Subjects completed a trial after $123 \pm 14.4 \mathrm{sec}$ on the spatial working memory-only task and after $118 \pm 11.1 \mathrm{sec}$ on the dual task $(t=0.502, \mathrm{df}=4, P>0.6)$.

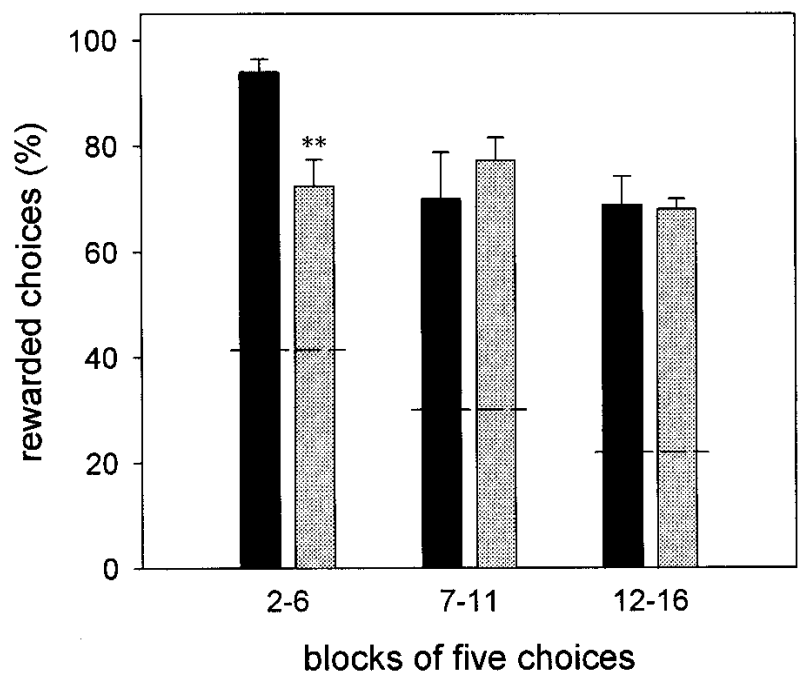

Figure 3 Rewarded choices (percentage, mean \pm SEM) with spatial working memory alone (black bars) and with combined working memory for spatial location and object-specific cues (gray bars).

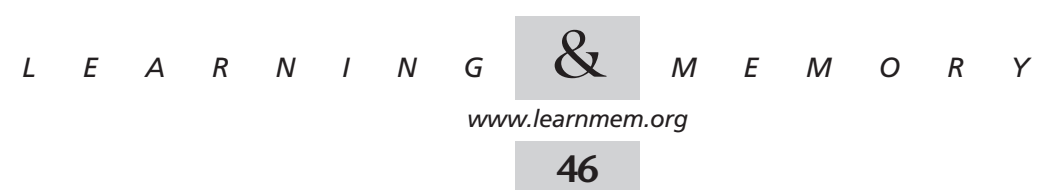


All individuals were scanning with a typical eye movement pattern. Stepwise turning of the head was followed by a period of fixation before the head was moved again. Often the head was slightly tilted. This tilt elevated the visual axis of one eye above the horizontal, whereas the visual axis of the other eye was directed toward the floor. Birds performed this movement pattern repeatedly during a trial and at several locations in the maze.

Frequently they did so when moving through the maze alley from A to B.

Although it cannot fully excluded that the birds also scanned details within the maze, it is likely that the birds were scanning extramaze landmarks on the walls.

\section{Experiment 2}

Overall performance as measured by the number of rewards obtained by the birds was $10.9 \pm 0.46$ with both eyes, $8.5 \pm 0.55$ with the left eye, and $9.2 \pm 0.81$ with the right eye. ANOVA with eye and block of trials as repeated measurements revealed a significant effect of eye $(F[2,8]=16.768, P<0.002)$ and a significant effect of blocks of choices $(F[2,8]=15.002, P<0.002)$. For further analysis of a possible lateralization, choices of the correct color and choices of correct location were considered separately. Figure 4 shows the number of correct color choices. ANOVA with eye and blocks of choices as repeated measurements revealed a main effect of eye $(F[2,8]=6.204$, $P<0.02)$ and a main effect of block of choices $(F[2,8]=8.258, P<0.01)$. Planned comparison of viewing conditions within the different blocks of five choices

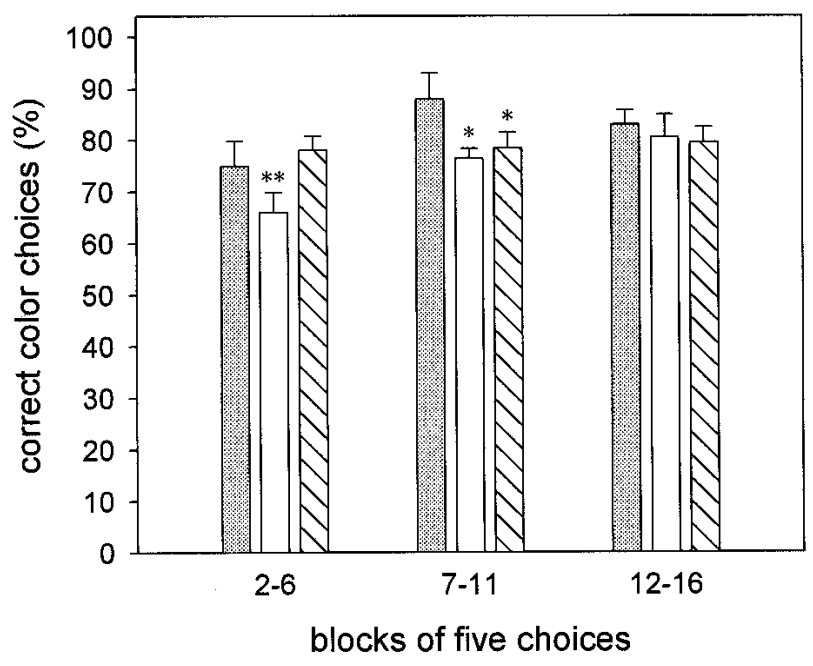

Figure 4 Test for lateralization of object-specific working memory. Correct color choices (percentage, mean \pm SEM) with both eyes (gray bars), and with the left eye (white bars, unfilled) or right eye (white bars, hatched) alone. Double asterisk indicates difference $(P<.01)$ from binocular and right eye performance; single asterisk indicates difference $(P<0.05)$ from binocular performance. showed that in the first block of five choices, performance with the left eye was significantly lower $(P<0.01)$ than both binocular performance and performance with the right eye, whereas there was no difference between binocular and monocular right performance $(P>0.4)$. During choices 7-11, performance in both monocular conditions was poorer than binocularly $(P<0.05)$, whereas there was no difference between the monocular conditions. During the last five choices, there were no differences. For the whole trial, left eye performance was lower than both binocular $(P<0.005)$ and right eye performance $(P<0.05$, one tailed), while there was no difference between binocular and right eye performance $(P>0.1)$.

A different pattern emerged in terms of spatial choices (Fig. 5). ANOVA with viewing condition and blocks of five choices as repeated measures revealed a significant main effect of viewing condition $(F[2,8]=12.205, P<0.005)$ and a significant main effect of blocks of choices $(F[2,8]=24.789, P<0.001)$. Planned comparisons within the blocks of five trials showed no difference between the conditions on the first or second block of five choices. On the third block, left eye performance $(P<0.005)$ and right eye performance $(P<0.01)$ were significantly lower than binocular performance. Over the whole trial, both left eye $(P<0.005)$ and right eye $(P<0.01)$ performance was poorer than under the binocular condition, whereas there was no difference between monocular conditions $(P>0.2)$

There was a trend $(F[2,8]=3.292, P=0.09)$ toward longer times until completion in the monocular conditions. Birds took $111 \pm 5.6 \mathrm{sec}$ on binocular trials, $143 \pm 7.3 \mathrm{sec}$ when using their left eye, and $152 \pm 23.4$ sec when using their right eye.

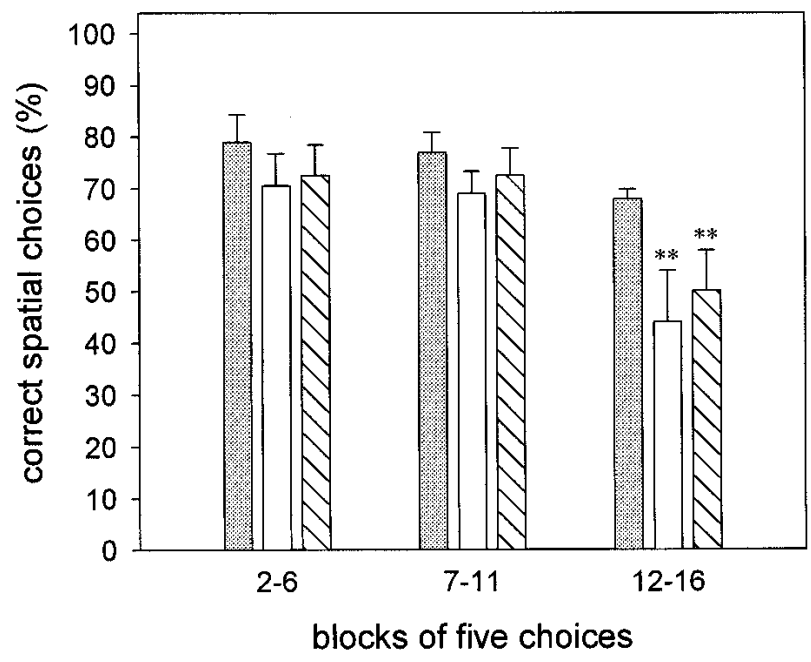

Figure 5 Test for lateralization of spatial working memory. Correct spatial choices (percentage, mean \pm SEM) with both eyes (gray bars) and with the left eye (white bars, unfilled) or right eye (white bars, hatched) alone. Double asterisk indicates difference $(P<.01)$ from binocular performance.

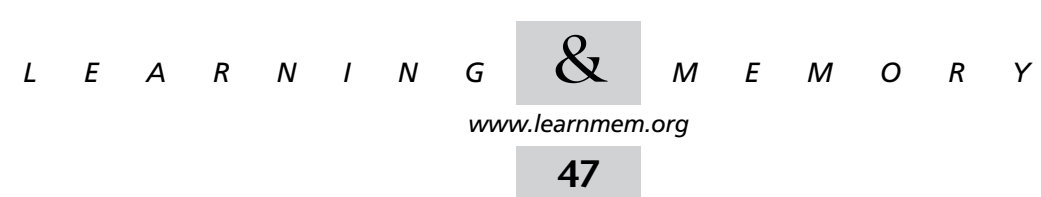


Monocular scanning movements were similar to those on binocular trials. When the head was tilted, usually the uncovered eye was elevated. This supports the view that scanning of extramaze landmarks was involved.

\section{DISCUSSION}

Our findings showed that pigeons are able to perform fairly efficiently a dual task involving spatial working memory and working memory for color cues signaling food. When compared with spatial working memory alone, overall performance on the dual task was only slightly impaired. The difference in choices leading to a reward for a complete trial was rather small (7\%). A considerable difference (23\%) occurred only during the first five choices. Pigeons could have achieved maximum performance on the first choices if they had been capable of one-trial learning. In that case, they would have learned from the first choice (not included in the scores) which color was correct and then made subsequent choices accordingly. Although one-trial learning of color that might require learning of a rule was not achieved, pigeons shifted very quickly to the correct color. Separate consideration of spatially correct choices indicated a decrement of $15 \%$ during the first five choices but only $3.5 \%$ for the whole trial. Thus, except for a rather brief period of adjustment, spatial working memory was not substantially impaired by flexible adjustment to prey-related color cues. Therefore, it is likely that pigeons use both types of memory in parallel to maximize foraging success.

Additional task requirements did not affect the time the pigeons took for completion of the task. Because performance speed is a sensitive measure of task difficulty, this further suggests that the dual task was not very demanding for the pigeons under binocular conditions. On both versions of the task, pigeons took $\sim 7$ sec per choice.

Separate consideration of spatial and color choices under monocular conditions suggests that the left brain hemisphere copes more efficiently with a change in the color that signals the reward than does the right brain hemisphere. Spatial performance was at the same level under both monocular conditions. The occurrence and direction of lateralization on the object-related component of the task is consistent with our predictions as well as with other studies on visual lateralization. In birds, there seems to be a left hemisphere advantage for the discrimination of object cues (Andrew 1991; Rogers 1996; Güntürkün 1997). Despite using different species and methods, this pattern of lateralization appeared to be fairly consistent. During food discrimination, such lateralization was found with unilateral pharmacological intervention in chickens (Rogers and Anson 1979) as well as with monocular occlusion in chicks (Mench and Andrew 1986) and pigeons (Güntürkün and Kesch 1987). Right eye superiority does not depend on differences in visual acuity (Güntürkün and Hahmann
1994). A higher degree of lateralization was related to better discrimination performance (Güntürkün et al. 2000). Furthermore, left-hemispheric superiority was not restricted to discrimination of natural food. It was found in pigeons memorizing a large number of black/white patterns (von Fersen and Güntürkün 1990) and possibly in New Caledonian crows manufacturing tools (Hunt 2000). Because the difference found between the left and the right eye in this dual-task experiment was most profound during the first choices within a trial, the question arises as to what distinguishes early choices in a trial from later choices. Two explanations are reasonable. First, the shift from selecting one color to selecting the other color might be dependent on a higher-order cognitive mechanism that organizes discrimination strategies. This superordinate cognitive mechanism could be lateralized in favor of the left brain hemisphere. Second, color discrimination during the first choices might have been more difficult than during later choices. In that case, lateralization would become visible along with increasing task difficulty but would be masked by a ceiling effect during less demanding stages of a trial. Both explanations are consistent with findings from a recent study on serial reversal learning in pigeons (Diekamp et al. 1999). In that study, there was no lateralization during initial color discrimination, but lateralization in favor of the left hemisphere emerged during serial reversal learning. Also in this case, increasing difficulty, along with higher task complexity and/or a higher-order cognitive mechanism, is a likely explanation.

On the spatial component of the task, the main effect was equal performance in the monocular conditions and higher performance in the binocular condition. In comparison with the lateralization pattern found on the color component of the dual task, this hints at differences in the way the brain hemispheres act and interact during discrimination of object-related and spatial cues. During discrimination of color cues, performance of the superior eye did not differ from binocular performance. This suggests that neural circuits within one hemisphere are able to run the necessary operations completely and independently. For spatial working memory, cooperation of brain systems linked to both eyes appears to be necessary to achieve maximum performance. There are two possibile explanations of how the use of both eyes could enhance performance above the level reached with one eye only. First, pigeons could use one or the other eye alternately when memorizing various views at different locations in the maze. This theory is supported by a recent study on active vision in chickens (Dawkins and Woodington 2000). When hens were orienting toward landmarks indicating the location of a reward, they repeated similar views on consecutive trials. In individual birds, particular views were linked to the same eye on consecutive trials although the patterns of eye use were not lateralized at the population level. If pigeons were using a

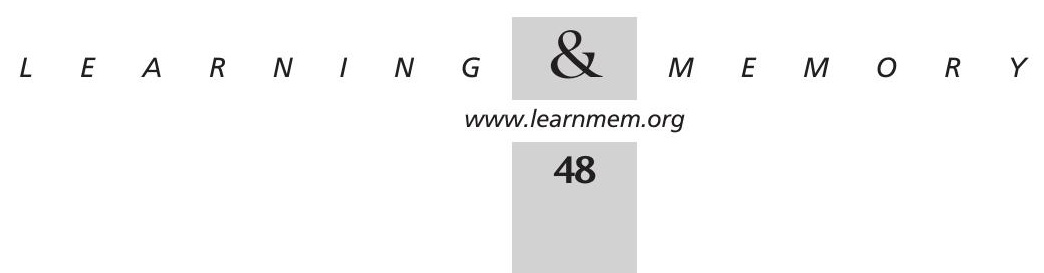


similar strategy, in that they preferentially use one of their eyes to view certain extramaze landmarks from a given position in the maze, the odds of correctly remembering individual sites should be enhanced if birds can use both eyes.

Alternatively, pigeons' orientation could be based on a panoramic view that integrates visual input from both eyes. In that case, the monocular view is less similar to the view stored in memory than the binocular view. Alhough present evidence does not allow us to decide between these possibilities, a recent study using a large, indoor, open field $(\mathrm{H}$. Prior, F. Lingenauber, J. Nitschke, and $O$. Güntürkün, in prep.) adds further support to the view that monocular visual spatial performance of pigeons, though worse than binocular spatial performance, is nevertheless highly precise with either eye. When searching for the position of a single goal, pigeons showed much higher performance binocularly than monocularly. If monocularly tested with all local cues removed or randomized and only distant global cues available, monocular performance with either eye was precisely focused on the location of the (no longer present) goal.

The lateralization pattern in pigeons appears to differ from that observed in chicks and food-storing birds. Whereas this study found no visuospatial lateralization, a study in homing pigeons revealed a left-hemisphere advantage (Ulrich et al. 1999). By contrast, using the method of monocular occlusion, Rashid and Andrew (1989) found superiority of the left eye/right hemisphere during spatial orientation in chicks. Both food-storing and non-food-storing parids and corvids relocated a feeder preferentially by spatial cues when using their left eye, and by object cues when using their right eye, after retention intervals of $5 \mathrm{~min}$ (Clayton and Krebs 1994a).

Although it is possible that bird species from different orders vary in their visuospatial lateralization, it should be considered that the nature of relevant spatial information is not exactly the same among different avian studies. For example, in homing pigeons, a likely reason for right-eye superiority is that the pigeons store a number of visual "snapshots" along their way home (Ulrich et al. 1999). In that case, that same left hemispheric superiority for visual long-term memory might be crucial in that it leads to a right-eye advantage in long-term memory for black/white pattern (von Fersen and Güntürkün 1990). In the case of food-storing birds, the facts turn out to be more complex if other studies using monocular occlusion are considered. When tested after retention intervals of $24 \mathrm{~h}$ or longer, the food-storing marsh tit (Parus palustris) demonstrated superiority of the right eye (Clayton 1993). This finding was corroborated in a study with monocular acquisition and binocular retrieval after retention intervals of 3, 7, and $24 \mathrm{~h}$ (Clayton and Krebs 1994b). Although information acquired by the left eye was present after $24 \mathrm{~h}$, as was information acquired via the right eye, the authors concluded that that task could be solved by either spatial or object-specific memory.

Regarding the experimental evidence from several avian studies, the testing of species from different groups under highly similar experimental protocols would appear to be a straightforward approach for resolving open questions. An advantage (but also a drawback) with regard to many of the established paradigms is that they are based on species-specific adaptations. A food-storing tit will not home from remote places, and a pigeon will not scatterhoard food. A way to at least partially circumvent this is by the use of complex laboratory settings, as described in this study. Food-storing birds can be tested for spatial working memory in mazelike settings (e.g., Balda and Kamil 1988), but to date they have not been tested for lateralization under these conditions.

To summarize, our results demonstrate efficient performance of foraging pigeons on spatial working memory and object-specific working memory in parallel. Furthermore, they reveal different patterns of lateralization for the objectspecific and the spatial component of a dual workingmemory task in a maze. Although left-hemispheric superiority on the object-specific component of the task corroborates findings from numerous other avian studies, symmetric monocular performance on the spatial-task component suggests that complementary memories or cooperation of both hemispheres is involved in pigeons' spatial orientation in a maze.

\section{MATERIALS AND METHODS}

\section{Experiment 1}

\section{Animals and Maintenance}

The subjects were five unsexed pigeons (Columba livia) obtained from local breeders, $\sim 1 \mathrm{yr}$ of age at the beginning of the experiment. They were kept in individual cages in a temperature-controlled room $\left(21^{\circ} \pm 1^{\circ} \mathrm{C}\right)$ on a $12: 12 \mathrm{~h}$ light : dark cycle. They had ad lib. access to drinking water and grit and were kept at $\sim 85 \%$ of their free-feeding weight throughout the experiment. None of the birds had any prior experience in behavioral experiments. Before pretraining, about one-half of the flight feathers were clipped. The birds then could only become airborne with great effort and would walk through the maze without trying to fly.

\section{Apparatus}

The maze (Fig. 1) was a rectangular arena $(250 \mathrm{~cm}$ long $\times 150 \mathrm{~cm}$ wide) made from plywood with walls $40 \mathrm{~cm}$ high. It contained 16 feeding sites. At each of the feeding sites there were two bowls of food, adjacent but separated by a wooden wall to force the pigeons to choose the color at a distance from which they were unable to look into the bowls. The bowls of flat, gray plastic were square shaped $(7 \times 7 \mathrm{~cm})$ and $6.5 \mathrm{~cm}$ high. The front, as viewed from the maze alley, and the inside bottom were in the relevant color (red, yellow). A whole-maize-grain food reward was always placed close to the front wall, so that the birds could only see the food after having approached the bowl within a few centimeters distance. The maze was placed on the floor in the center of an experimental

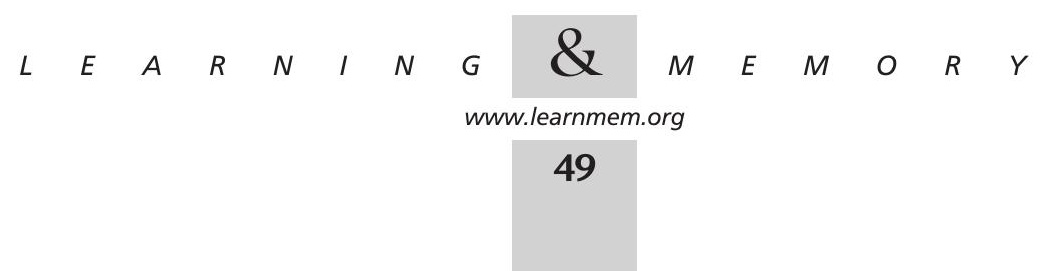


room $(550 \mathrm{~cm}$ long $\times 350 \mathrm{~cm}$ wide $\times 400 \mathrm{~cm}$ high). On the walls of the room there were several landmarks, for example, a poster and differently shaped and painted "trees" made of cardboard.

\section{Procedure}

Each subject was given one daily trial. Initially, animals were given five exploration trials during which one gray food bowl was placed at each of the 16 sites. On the first of these trials, a few grains of maize were laid out visibly in front of each bowl to direct the bird's attention to the food. After exploratory training all birds were approaching the food bowls immediately, and stage 1 of the training began. During this stage, only one color was rewarded (red for three birds, yellow for two birds) and the position of the bowls at each of the 16 maze locations varied to a pseudorandom schedule. Pseudorandom sequences followed the criteria suggested by Gellerman (1933) and were based on sequences by Fellows (1967), which were adjusted for the number of choices. At the beginning of a trial, each individual was placed at position A or B (Fig. 1) of the maze under very dim lighting conditions so that the birds would remain still.

When the experimenter had left the maze, the turning on of the room lights started the trial. Turning the lights off after a bird had made 16 choices finished the trial. A choice was counted each time the head of the bird had passed the edge of the separation between the food bowls. To obtain the maximum reward, a subject had to visit each feeding site only once and always choose the correct color. Animals were trained for 40 trials, at which point they had reached asymptotic performance levels. Then they received a block of 10 test trials, which followed the same procedure as the training trials. Subsequently, reversal training began. The rewarded color was switched, and after achieving criterion of $80 \%$ correct color choices within a trial the rewarded color was switched again, and so on.

This was repeated until the birds achieved criterion on the first trial. On reaching this performance level, birds were given a second block of 10 test trials during which the reward changed from trial to trial according to a pseudorandom schedule (criteria as mentioned above). Thus, the birds had to learn within single trials which color was rewarded. A spatial working memory error was counted every time a bird chose a feeding site visited before, and an object-specific working memory error was counted each time a subject chose the incorrect color. Choice of the incorrect color at a site not visited before was considered spatially correct.

\section{Data Analysis}

Experiments were observed and recorded via a VCR system. Of the 16 choices within a trial, the first choice was $100 \%$ correct in terms of the spatial aspect by definition. Regarding the color, the first choice is expected to be (and was) at random (50\%). Therefore, only choices 2-16 were informative about learning and were included in the analysis. In addition to overall performance, blocks of five choices $(2-6,7-11,12-16)$ were combined to provide an estimate of performance in the beginning, the middle, and toward the end of a trial.

Random performance for a color choice is $50 \%$ throughout a trial, whereas random performance level of the spatial component of the task is becoming lower because of the decreasing proportion of baited sites as more rewards are taken. Random expectation can be calculated by the formula $P=([n-1] / n)^{c-1}$, with $n=16$ being the total number of sites and $c$ being the order number of a given choice. Thus, random expected probability for the spatial component of the task alone is 4.14 correct choices (82.7\%) for the first block of five choices, 3.00 (59.9\%) for the second block, 2.17 (43.4\%) for the third block, and 9.65 (64.3\%) for the whole trial. For the combined task, the random expectation is $41.4 \%$ for the first block of five choices, $30.0 \%$ for the second block, $21.7 \%$ for the third block, and $32.2 \%$ for the whole trial. Comparison between the task with spatial working memory alone and the combined task is based on means for 10 trials; data for the reversal stage are based on single trials. Comparison with random performance was made with one-sample $t$ tests. Comparison of trials with and without objectspecific working memory was made by ANOVA, with memory condition and blocks of choices as repeated measures. This analysis was followed by planned comparisons of the two memory conditions within each block of trials.

\section{Experiment 2}

\section{Animals and Setting}

The same birds used in Experiment 1 served as subjects, and the same maze was used.

\section{Monocular Occlusion}

After the Experiment 1 trials were finished, birds were prepared for wearing eye caps of circular cardboard that were fitted by means of Velcro (cf. Ulrich et al. 1999). Velcro rings (diameter: $16 \mathrm{~mm}$ inside, $26 \mathrm{~mm}$ outside) were affixed around the pigeons' eyes by means of water-soluble nontoxic glue, after clipping a circular strip of feathers. The counterpiece of the Velcro ring was glued to the circular eye cap. The cardboard eye caps could be bent easily, which allowed us to fit them tightly on individual pigeons' head.

\section{Procedure}

Pigeons were trained first to master the maze with eye caps. Initially, they were given two trials with Velcro rings but without eye caps. Subsequently, they were given six habituation trials with eye caps: Three with the eye caps on the right and three with the eye caps on the left side in a balanced order.

Birds then received 24 test trials on the dual task: Eight with the left eye seeing, eight with the right eye seeing, and eight binocularly, in a balanced order. The same combination of color and eye cap was not repeated on consecutive sessions, and the color shifted between consecutive trials as often as it was left the same.

\section{ACKNOWLEDGMENTS}

We thank Peter Midford for critical reading of the manuscript and the Deutsche Forschungsgemeinschaft, SFB Neurovision, for financial support.

The publication costs of this article were defrayed in part by payment of page charges. This article must therefore be hereby marked "advertisement" in accordance with 18 USC section 1734 solely to indicate this fact.

\section{REFERENCES}

Andrew, R.J. 1991. The nature of behavioural lateralization. In Neural and behavioural plasticity: The use of the domestic chick as a model (ed. R.J. Andrew), pp. 536-554. Oxford University Press, Oxford.

Balda, R.P. and Kamil, A.C. 1988. The spatial memory of Clark's nutcrackers (Nucifraga columbiana) in an analogue of the radial arm maze. Anim. Learn. Behav. 16: 116-122.

Benhamou, S. 1994. Spatial memory and searching efficiency. Anim. Behav. 47: 1423-1433.

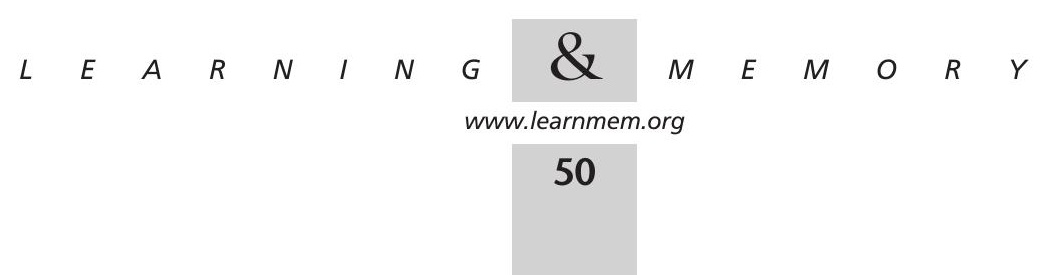


Bond, A.B., Cook, R.G., and Lamb, M.R. 1981. Spatial memory and the performance of rats and pigeons in the radial-arm maze. Anim. Learn. Behav. 9: 575-580

Bradshaw, J.L. and Rogers, L.J. 1993. The evolution of lateral asymmetries, language, tool use, and intellect. Academic Press, San Diego.

Clayton, N.S. 1993. Lateralization and unilateral transfer of spatial memory in marsh-tits. J. Comp. Physiol. A 171: 807-815.

Clayton, N.S. and Krebs, J.R. 1994a. Memory for spatial and object-specific cues in food-storing and non-storing birds. J. Comp. Physiol. A 174: 371-379.

. 1994b. Lateralization and unilateral memory transfer in marsh tits: Are two eyes better than one? J. Comp. Physiol. A 174: 769-773.

Cook, R.G., Brown, M.F., and Riley, D.A. 1985. Flexible memory processing by rats: Use of prospective and retrospective information in the radial maze. J. Exp. Psychol. Anim. Behav. Proc. 11: 453-469.

Croy, M.I. Hughes, R.N. 1991. Effects of food supply, hunger, danger and competition on choice of foraging location by the fifteen-spined stickleback, Spinachia spinachia L. Anim. Behav. 24: 131-139.

Dawkins, M.S. and Woodington, A. 2000. Pattern recognition and active vision in chickens. Nature 403: 652-655.

Diekamp, B., Prior, H., and Güntürkün, O. 1999. Functional lateralization, interhemisheric transfer and position bias in serial reversal learning in pigeons (Columba livia). Anim. Cogn. 2: 187-196.

Dukas, R. 1998. Constraints on information processing and their effects on behavior. In Cognitive ecology (ed. R. Dukas), pp. 89-127. University of Chicago Press, Chicago.

Fellows, B.J. 1967. Chance stimulus sequences for discrimination tasks. Psychol. Bull. 67: 87-92.

Garber, P.A. 1989. Role of spatial memory in primate foraging patterns: Saguinus mystax and Saguinus fuscicollis. Am. J. Primatol. 19: $203-216$.

Gellerman, L.W. 1933. Chance orders of alternating stimuli in visual discrimination experiments. J. Genet. Psychol. 42: 207-208.

Güntürkün, O. 1997. Avian visual lateralization: A review, Neuroreport 8: $3-11$.

Güntürkün, O. and Hahmann, U. 1994. Visual acuity and hemispheric asymmetries in pigeons. Behav. Brain Res. 60: 171-175.

Güntürkün, O. and Kesch, S. 1987. Visual lateralization during feeding in pigeons. Behav. Neurosci. 101: 433-435.

Güntürkün, O., Diekamp, B., Manns, M., Nottelmann, F., Prior, H., Schwarz, A., and Skiba, M. 2000. Asymmetry pays: Visual lateralization improves discrimination success in pigeons. Curr. Biol. 10: $1079-1081$

Healy, S.D. and Hurly, T. A. 1998. Rufous hummingbirds' (Selasphorus rufus) memory for flowers: Patterns or actual spatial locations? J. Exp. Psychol. Anim. Behav. Proc. 24: 396-404.

Hunt, G.R. 2000. Human-like, population-level specialization in the manufacture of pandanus tools by New Caledonian crows Corvus moneduloides. Proc. R. Soc. Lond. B 267: 403-413.

Kamil, A.C. 1978. Systematic foraging by a nectar-feeding bird, the amakihi (Loxops virens). J. Comp. Physiol. Psychol. 92: 388-396.

Kesner, R.P. and Spain, M.J. 1988. Correspondence between rats and humans in the utilization of retrospective and prospective codes. Anim. Learn. Behav. 16: 299-302.

Krebs, J.R., Erichsen, J.T., Webber, M.I., and Charnov, E.L. 1977. Optimal prey selection in the great tit, Parus major. Anim. Behav. 25: 30-38.

Lewis, A.C. 1986. Memory constraints and flower choice in Pieris rapae. Science 232: 863-865.

Mench, J.A. and Andrew, R.J. 1986. Lateralization of a food search task in the domestic chick. Behav. Neur. Biol. 46: 107-114.

Murton, R.K. 1971. The significance of a specific search image in the feeding behaviour of the wood-pigeon. Behaviour 40: 10-42.

Olton, D.S., and Samuelson, R.J. 1976. Remembrance of places passed: Spatial memory in rats. J. Exp. Psychol. Anim. Behav. Proc. 2: 97-116.

Pietrewicz, A.T. and Kamil, A.C. 1979. Search image formation in the blue jay (Cyanocitta cristata). Science 204: 1332-1333.

Pulliam, H.R. 1981. Learning to forage optimally. In Foraging behavior: Ecological, ethological, and psychological approaches (eds. A.C. Kamil and T.D. Sargent), pp. 379-388. Garland, New York.

Rashid, N. and Andrew, R.J. 1989. Right hemisphere advantage for topographical orientation in the domestic chick, Neuropsychologia 27: 937-948.

Roberts, W.A. and Van Veldhuizen, N. 1985. Spatial memory in pigeons on the radial maze. J. Exp. Psychol. Anim. Behav. Proc. 11: 241-260.

Rogers, L. 1996. Behavioral, structural and neurochemical asymmetries in the avian brain: A model system for studying visual development and processing. Neurosci. Biobehav. Rev. 20: 487-504.

Rogers, L.J. and Anson, J.M. 1979. Lateralisation of function in the chicken forebrain. Pharmacol. Biochem. Behav. 10: 679-686.

Sherry, D.F. 1998. The ecology and neurobiology of spatial memory. In Cognitive ecology (ed. R. Dukas), pp. 261-296. University of Chicago Press, Chicago.

Sherry, D.F. and Schacter, D.L. 1987. The evolution of multiple memory systems. Psychol. Rev. 94: 439-454.

Spetch, M.L. 1990. Further studies of pigeons' spatial memory in the open-field task. Anim. Learn. Behav. 18: 332-340.

Spetch, M.L. and Edwards, C.A. 1986. Spatial memory in pigeons in an open-field feeding environment. J. Comp. Psychol. 100: 266-278.

- 1988. Pigeons' (Columba livia) use of global and local cues for spatial memory. Anim. Behav. 36: 293-295.

Spetch, M.L. and Honig, W.K. 1988. Characteristics of pigeons' spatia working memory in an open-field task. Anim. Learn. Behav. 16: 123-131.

Ulrich, C., Prior, H., Duka, T., Leshchins'ka, I., Valenti, P, Güntürkün, O., and Lipp, H.-P. 1999. Left-hemispheric superiority for visuospatial orientation in homing pigeons. Behav. Brain Res. 104: 169-178.

Vallortigara, G., Rogers, L.J., and Bisazza, A. 1999. Possible evolutionary origins of cognitive brain lateralization. Brain Res. Rev. 30: 164-175.

Von Fersen, L. and Güntürkün, O. 1990. Visual memory lateralization in pigeons. Neuropsychologia 28: 1-7.

Received August 8, 2000; accepted in revised form December 20, 2000.

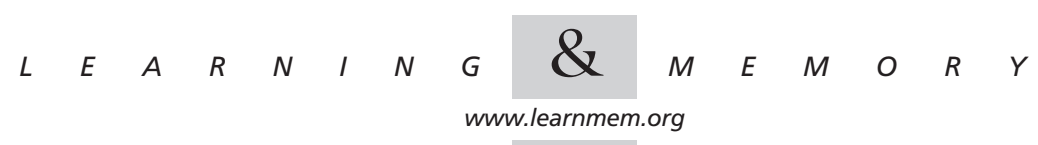




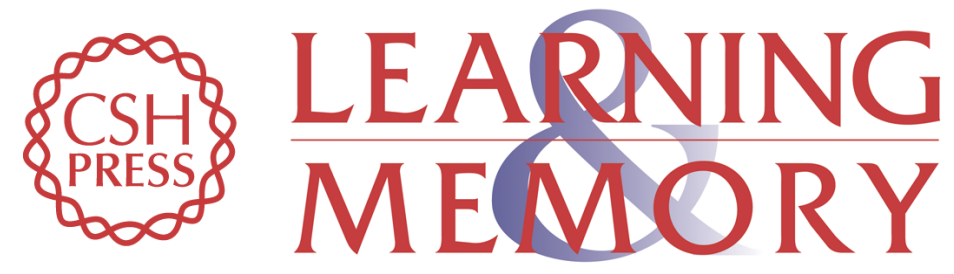

Parallel Working Memory for Spatial Location and Food-Related Object Cues in Foraging Pigeons: Binocular and Lateralized Monocular Performance

Helmut Prior and Onur Güntürkün

Learn. Mem. 2001, 8:

Access the most recent version at doi:10.1101//m.36201

References This article cites 38 articles, 2 of which can be accessed free at: http://learnmem.cshlp.org/content/8/1/44.full.html\#ref-list-1

License

Email Alerting Receive free email alerts when new articles cite this article - sign up in the box at the Service top right corner of the article or click here. 